\title{
JOURNEY OF MOBILE GENERATION AND COGNITIVE RADIO TECHNOLOGY IN 5G
}

\author{
Parnika De and Shailendra Singh \\ Department of Engineering and Application, National Institute of Technical Teacher \\ Training and Research, Bhopal, India.
}

\begin{abstract}
The ever increasing number of smart network devices may reach up to 24 billion in year 2020 as stated in the recent survey conducted by Forbes magazine. This may obsolete the current $4 G$ technology for handling smart bandwidth allocation to such a large number of devices. In order to cope the challenging need for fast and efficient data transfer over these devices, demands next generation mobile network technology. In literature 5G technology has been suggested that offers appropriate solution to the above issues. $5 G$ is a futuristic technology that would solve many problem of day to day life. By using $5 G$ high data rates can be achieved in the range of Gbps with minimal latency. But the question is how to make such futuristic technology realistic. This can be done by efficiently utilizing the bandwidth in the allotted spectrum. Despite numerous benefits, $5 G$ may critically suffer from tedious implementation problems that have been discussed in this paper. Cognitive radio $(C R)$ is an intelligent radio that works on the principle of dynamic spectrum allocation. Cognitive Radio is capable of learning and adapting to external environment and reuses the frequency when primary user is absent. This paper combine the advantage of two technology $5 G$ terminal and Cognitive radio terminal where $5 G$ provide quality of service and high data rate whereas Cognitive radio give flexibility and adaptability to $5 G$.
\end{abstract}

\section{KEYWORDS}

5G, Cognitive Radio, Spectrum Sensing, Resource Allocation

\section{INTRODUCTION}

Inception of wireless technology happened in 1970s [1]. Technological advancement in mobile wireless technology is classified into different generation. All of it started from 1G technology soon followed by $2 \mathrm{G}$ technology in which analog signal communication is replaced with digital signal communication. Data and voice simultaneous communication is allowed in $3 \mathrm{G} .4 \mathrm{G}$ technology which provide ultra-broadband network and matches demand of new network equipment. But in this era of networking, with increasing number of smart devices connecting to the network every day, even coming 4G technology cannot handle the network load efficiently. Solution of the problem for efficient and faster data transfer comes in the form of a new generation network technology called as $5 \mathrm{G}$ mobile network. $5 \mathrm{G}$ is next generation mobile Communication network which has been proposed to bring together the existing wireless and wired communication into an all Internet protocol high performance worldwide network. The fifth generation mobile network technology is based on cognitive radio (CR). CR act as backbone for $5 \mathrm{G}$ network and provide very good solution to the spectrum utilization. CR is an intelligent radio that works on principle of intelligent implementation of resources. Cognitive Radio is capable of learning and adapting to external environment and reuses the frequency when primary user is absent. 


\section{LITERATURE SURVEY}

Major concern of research paper is to highlight about three major topic i.e. 5G, Cognitive Radio and 5G using Cognitive Radio. Since the proposal of 5G and Cognitive Radio research community has contributed a lot covering almost all major topics from both the domain. $5 \mathrm{G}$ using Cognitive Radio is quite a newbie, so still there exist vast scope of research which includes discovering areas for implementing $\mathrm{CR}$ in $5 \mathrm{G}$, Suitable algorithm for $5 \mathrm{G}$ and many other areas are yet waiting for discovery. Since there exist enormous amount of work done in the all the three area, literature review only covers about recent and basic research work done. There exist no clear history when it was proposed but some of the starting program for its implementation has been started in year 2008 by NASA and south Korean agency [2]. After the proposal of 5G many researcher started looking $5 \mathrm{G}$ as the solution all the futuristic mobile communication problem. Hence in result many research proposal and paper came discovering various scope of the $5 \mathrm{G}$ network. In [3]-[9] authors has discussed about different mobile generation, they also suggested about use of 5G up to year 2013 and 2014 because of the data traffic. This survey paper is one of the pioneer research paper suggesting about use of $5 \mathrm{G}$ in coming future. Like any other network $5 \mathrm{G}$ has its own features and requirements keeping this in mind many researchers has suggested about features, requirement and kind of technologies adopted for fulfilling these requirements, these topics were already discussed in the section 3 of paper. Based on earlier research papers works three Indian researchers has proposed specific protocols for each of the OSI layer [7],

Table 1. Showing Stack Protocol and Services available at the Particular Layer

\begin{tabular}{|c|c|}
\hline Layers & Protocol and sub-layer \\
\hline Application Layer & Services \\
\hline Transport Layer & Open Transport Protocol \\
\hline \multirow{2}{*}{ Network Layer } & Upper layer \\
& Network translation layer \\
\cline { 2 - 2 } & Lower layer \\
\cline { 2 - 2 } & Wireless architecture \\
\cline { 2 - 2 } & \\
\hline
\end{tabular}

After this paper many protocols were proposed at each level, with major concern of the authors as physical layer [10]-[13] and application layer as major concern some of the university thesis has tried to suggest protocols and services at the physical layer, one such thesis is proposed [14] which take care of smartest allocation of resources providing smartest bandwidth allocation service.

Idea of Cognitive radio was proposed by Mitola in his paper [15] along with Gerald Q. Maguire Jr. basic goal behind proposal is efficient utilization of resources. For maintaining proper utilization of resources there must exist communication between different network devices for that Mitola has proposed a new language called as RKRL (radio language representation language), carrying forward the research work of Mitola, FingGe and et.al [16] has proposed a new cognitive engine based method was suggested which collects data from different sensor and tried to optimize the network. As explained in the section 6 one of the major cognitive radio implementations is found in the spectrum sensing in literature also many researcher has used cognitive radio for spectrum sensing and then spectrum allocation with the help of data collected at the physical layer [16]-[18].After wide literature survey, we have concluded as par our knowledge about CR using 5G, there exist not much work done in this area, in one of the paper [19] researchers has tried to made bridge between both the concept with the help of similarities between both the techniques and in another work researchers were discussing about effect of 
using CR into 5G. They have done analysis of various architecture and trade-off between spectral efficiency and energy efficiency [20]. In discussion of topic they divided radio resource into two parts, comparison is shown in the table. Along with the cognitive radio in parallel, other were also working to increase efficiency of network paradigm one such technology is smart antenna also known from the name intelligent antenna, it is consider as one of the most close rival of cognitive radio. Smart antenna was firstly used in the 1980's for military application up to 1990's it is available or the commercial application with basic principle explained as follows: "analysis of signal directional with the help of signal processing and can adapt itself using beam forming techniques" [21]. There is generally two type of smart antenna switched beam and adaptive array [21]. Due to certain demerits it is not preferred over cognitive radio. Disadvantages are discussed in detail the [22] such as expensive, larger in size, complex for implementation and adjustment of location for optimal operation. Now a days researchers are trying to develop system which can take advantages of both cognitive radio and smart antennas.

Table 2. Comparison between Licensed and Cognitive RR

\begin{tabular}{|c|c|c|c|}
\hline Type of radio resource (RR) & Bandwidth & Transmit power & Reliability \\
\hline Licensed RR & Small & High & High \\
\hline Cognitive RR & Broad & Low & Low \\
\hline
\end{tabular}

\section{MobiLe Generations}

Telephone remained most popular mode of communication until dawn of wireless communication. Marconi known as father of wireless communication suggested these ideas in late $19^{\text {th }}$ century [8]. Wireless technology is divided in to three periods according to its technologies adopted.

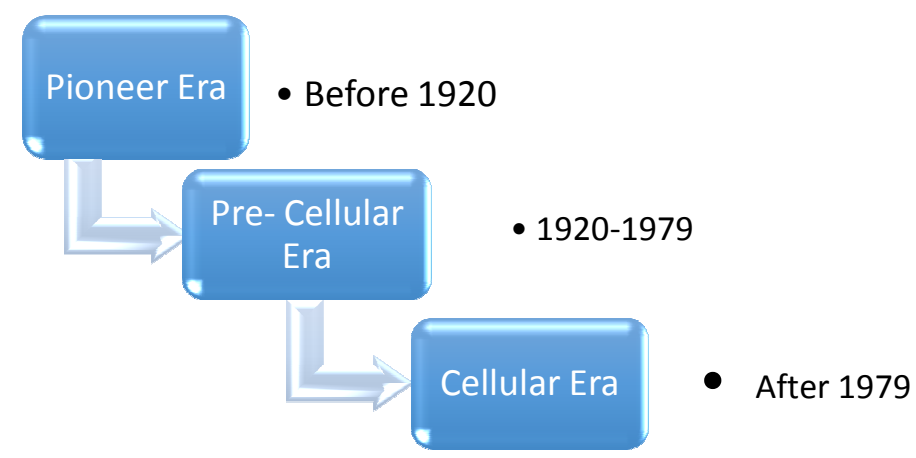

Figure 1. Different Period in Wireless Communication.

Other than zeroth generation of mobile technology all others belong to cellular era. Dawn of cellular technology brought new revolution in wireless communication. Through cellular technology re-allocation of frequency band is possible which in turn gives features of reusability of frequencies and saves energy.

\subsection{ZEROTH GENERATION (OG)}

Zeroth Generation Technology also know from the name Mobile Radio Telephone System, uses analog signal for communication as a carrier of information and it is based on public switched telephone network. Since cellular technology was not invented until time this system belongs to pre cellular era. Zeroth Generation is based on following mobile Technologies Device has two 
components Transceiver and Head. Transceiver is mounted on the roof of the vehicle and head is component through which communication take place contains display, receiver and dial. System support only 25 channels in the range of $20 \mathrm{KMs}$, hence it support only limited amount of users. Following are the reasons due to which researchers and users felt the need of new mobile technology [7]:

- Half duplex in nature i.e. only one user should be in active state other in passive state.

- Analog in nature affected by noise.

- Huge in size, so cumbersome to handle device.

- Roaming facilities is not supported Technologies

- Advance Mobile Telephone

- Mobile Telephone System (MTS)

- Mobile Telephone System D (MTSD)

- Land Mobile TeleFoni (OLT)

- Push to Talk (PTT)

- Improved Mobile Telephone Service (IMTS)

\subsection{Zero Point Five Generation (0.5G)}

Cellular technology was firstly deployed in $0.5 \mathrm{G}$ mobile technology with network divided in to multiple zones, each zone is a cell of size $30 \mathrm{KMs}$ leaving all other features almost same as that of the $0 \mathrm{G}$, because of limitations like bulky and expensive in nature. Autotel came into existence also known as PALM (Public Automated Land Mobile) which uses digital signals for call set up, channel allocation and ringing, still voice signal is transmitted through analog waveform. Instead of using cellular architecture PALM uses VHF.

\subsection{First Generation Mobile TeChnology (1G)}

$1 \mathrm{G}$ was introduced in the year 1980, based on cellular technology which follows analog technology for making calls [8]. Dawn of cellular technology solve the problem of limited number of users for particular frequency band, that means same frequency can be used by number of users which in turn enhances throughput of network. All allotment of frequency take place at base station. To solve single way transmission i.e. half duplex problem, every call has pair of dedicated channels. Packet switched network is responsible for data transmission in 1G. In different geographical location various standards were followed like Advance Mobile Phone Service, Nordic Mobile Telephone (NMT) and Total access Communication System (TACS) [8]. Considering ill effect of analog communication such as security and noise gave inspiration to researcher for next generation mobile communication.

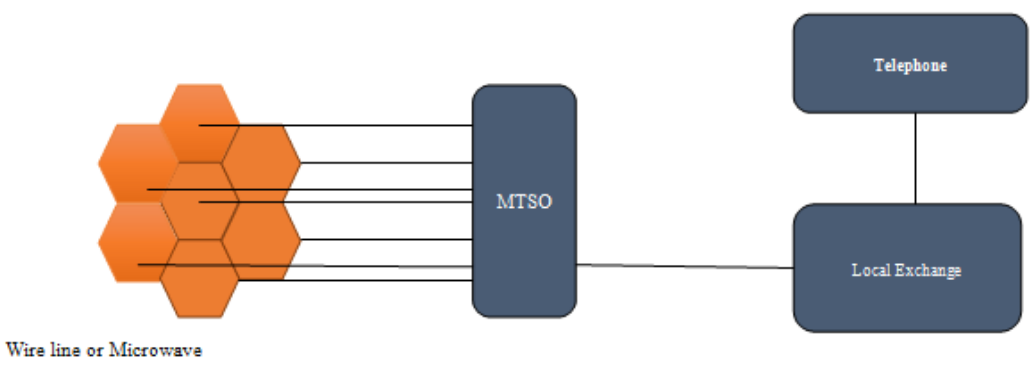

Figure 2 Showing Cellular Architecture of 1G [8] 


\subsection{SeCONd Generation Mobile TeChNOLOGy (2G)}

Mobile generation is introduced in year 1991, many countries are still using this generation for communication. Communication is based on digital signals irrespective of its ancestor's approach of analog signals. Digital signals brought removes many shortcomings of predecessor generations such as earlier channels suffers from noise where as digital signals are less prone to noise and security was also big problem which can be solved with the help of digital encryption.

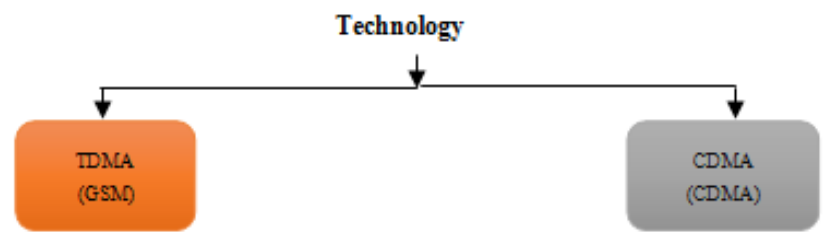

Figure 3 Shows Technologies Available in $2^{\text {nd }}$ Generation Mobile Technology

Other than voice calling $2 \mathrm{G}$ also support various other application like SMS (short messaging service, first time introduce to utilize vacant band and send message from receiver to sender), data transmission service with the help of GPRS( General Packet Radio Service).

\subsubsection{MARKETING SUCCESSOR OF $2 \mathrm{G}$}

\section{A. 2.5G (GSM or GPRS)}

\section{Packet switched domain + circuit switch domain $=2.5 \mathrm{G}$}

In $2.5 \mathrm{G}$ instead of following circuit switch domain between sender and receiver, it is also based on packet switched domain i.e. In reality it do not follow any of the switching method instead a hybrid approach where a single circuit is shared among many users and each user is charged according to number of data packets transferred.

Application supported by $2.5 \mathrm{G}$ are MMS (multimedia messaging service) and one of the most important service provided by $2.5 \mathrm{G}$ is WAP which enabled browsing on the mobile phone earlier due to weak hardware configuration of mobile, browsers were not supported on mobile.

\section{B. 2.75G (EDGE)}

$2.75 \mathrm{G}$ is pre- $3 \mathrm{G}$ technology which is standardized by $3 \mathrm{Gpp}$ with the goal of higher data rate per channel which is achieved with the help of coding and transmitting data. This new technology introduce new technique of modulation and protocol enhancement method for transmitting packet. It uses nine modulation scheme with coding schemes where four are based on GMSK and five are based on 8PSK modulation [8]. It is also known with the name EDGE (Enhanced data rates for GSM evolution). Most important benefit of using EDGE is that it does not need any network architectural change instead it works on GSM architecture.

\subsection{THIRD GENERATION (3G)}

Inception of $3 \mathrm{G}$ is for providing users mobile broadband, it can support various applications like video calling, live streaming, mobile internet access and IPTv for supporting these application it is based on any of the three technologies such as CDMA 2000, TD-SCDMA and W-CDMA. 
According to some researchers they do not consider $3 \mathrm{G}$ as a mobile technology instead of that they have view it as a set of network protocol [8].

\subsubsection{MARKETING SUCCESSORS OF 3G}

\section{A. 3.5G}

3.5G is combination of two protocols HSDPA and HSUPA which follow all the standards and rules of WCDMA. Basic purpose of HSPA is to reduce latency with help of technological improvement and able to reduce latency up to 5 times

\section{HSDPA + HSUPA $=3.5 \mathrm{G}(\mathrm{HSPA})$}

$H S D P A$

This protocol is more suitable for data centric applications where greater speed of download is required in comparison to up speed.

Technologies:

- Modulation: Instead of using QPSK 16-QAM scheme is used.

- FastHARQ: Hybrid Automatic Repeat Request is implemented with multi code operation. So that all receivers will get equal data rate irrespective of its distance from Base Station.

- Scheduling: Allocating even smaller slot of time to users and handling data traffic at the Base Station intelligently.

- Scheduling: Additional channels allow more users to access network concurrently.

- HSUPA

- This technology is applied for uplink at the user end. Almost all the technologies used here is same as that of the HSDPA

Characteristics:

- Data Rate: Increased Data rate up to $5.74 \mathrm{Mbps}$

- Latency: Lower latency having TTI value of $2 \mathrm{~ms}$

- System Capacity: Improved system capacity with higher number of users

- Modulation: 64-Qam scheme is used.

- Hybrid $A R Q$

- Fast Packet Scheduling

\section{A.3.75G (HSPA+ or Evolved HSPA)}

Benefit of HSPA+ over HSPA is that it support higher data transfer rate, reduces latency and backhaul is addressed. Major features and technologies used in $3.75 \mathrm{G}$ is as follows:

- $\quad M I M O$ : If signal strength is high higher modulation is used to increase through put.

- PacketConnectivity: For transmitting data rapidly reconfiguration of HS-DSCH and EODCH channels is done.

- CELL_FACHoperation: It keeps active packet connectivity in ideal period.

- Layer 2 Protocol: MAC-hs protocol has been introduce to take full advantage of HS$\mathrm{DSCH}$

- It is clear from above table statistically HSPA+ seems to be better choice than general LTE Technology, still LTE is considered over it because: 
- LTE support wider Bandwidth.

- OFDM modulation enable data to send through multi resilient path and propagation effects.

Table 3. Shows Comparison between HSPA+ and LTE [14]

\begin{tabular}{|c|c|c|}
\hline Channel Bandwidth (MHz) & HSPA+ Data Rate (Mbs) & LTE Data Rate (Mbps) \\
\hline 5 & 42 & 37 \\
\hline 10 & 84 & 73 \\
\hline 20 & NA & 150 \\
\hline
\end{tabular}

\subsection{FOURTH GENERATION (4G)}

It is design to support all the modern application of today's world like mobile web access, IP telephony, gaming services, high definition mobile TV, Video conferencing and 3D television which cannot be supported by previous mobile generation. For supporting these much applications 4G need to modify architecture of mobile technology from its base i.e. from the Physical layer: MIMO- multiple antennas and multi user MIMO system is used for utilizing spectrum efficiently.

- Downlink utilize multi carrier frequency and for uplink single carrier frequency domain equalization (SC-FDE).

- Advance antenna system: there are two type of antenna systems spatial multiplexing and closed loop multiple antenna technologies.

- Software defined Radio

- For providing services based on $4 \mathrm{G}$ vendors follow one of these format: WiMax and LTE.

\section{Fifth Generation Mobile Technology (5G)}

$5 \mathrm{G}$ is futuristic mobile technology which will be a successor of $4 \mathrm{G}$ network technology. Aim and purpose of $5 \mathrm{G}$ is very much different than its predecessor which is to introduce mobile broadband. Goals of $5 \mathrm{G}$ cannot be achieved with the help of current infrastructure and architecture of network technology, for that everything in current mobile generation has to either redefine or built it from scratch. There are various issues regarding shifting from $4 \mathrm{G}$ to $5 \mathrm{G}$ which are listed below [3], [5]-[9], [23]:

Table 4. Shows Comparison between Different Generations of Mobile

\begin{tabular}{|c|c|c|c|c|c|c|}
\hline Generation & Upspeed & DownSpeed & Technology & Standard & Year & Frequency \\
\hline $0 \mathrm{G}$ & NA & $\mathrm{NA}$ & Pre-cellular & $\begin{array}{l}\text { AMTS, MTD, } \\
\text { OLT, PTT }\end{array}$ & Early $1970 \mathrm{~s}$ & $150 \mathrm{MHz}$ \\
\hline $0.5 \mathrm{G}$ & $\mathrm{NA}$ & $\mathrm{NA}$ & VHF, Cellular & MTS,IMTS & 1971 & $150 \mathrm{MHz}$ \\
\hline $1 \mathrm{G}$ & $2.4 \mathrm{Kbps}$ & $1.3 \mathrm{Kbps}$ & Analog Cellular & AMPS & 1981 & $150 \mathrm{MHz}+$ \\
\hline $2 \mathrm{G}$ & $64 \mathrm{Kbps}$ & $32 \mathrm{Kbps}$ & Digital Cellular & TDMA,CDMA & 1991 & $\begin{array}{l}900 \mathrm{MHz}, 1800 \\
\mathrm{MHz}\end{array}$ \\
\hline $2.5 \mathrm{G}$ & $144 \mathrm{Kbps}$ & $72 \mathrm{Kbps}$ & $2 \mathrm{G}+\mathrm{GPRS}$ & TDMA, CDMA & 1997 & $450 \mathrm{MHz}$ \\
\hline $2.75 \mathrm{G}$ & 1Mbps & $500 \mathrm{Kbps}$ & $\begin{array}{l}\text { GSM core } \\
\text { Network }\end{array}$ & TDMA & 1998 & \\
\hline $3 \mathrm{G}$ & $2 \mathrm{Mbps}$ & TMbps & Broad Band & $\begin{array}{l}\text { WCDMA, } \\
\text { CDMA2000 }\end{array}$ & 2001 & $2100 \mathrm{MHz}$ \\
\hline $3.5 \mathrm{G}$ & $14 \mathrm{Mbps}$ & $5.76 \mathrm{Mbps}$ & HSPA & WCDMA & 2008 & \\
\hline $3.75 \mathrm{G}$ & $42 \mathrm{Mbps}$ & $34 \mathrm{Mbps}$ & HSPA+ & $\begin{array}{l}\text { Multiple antenna } \\
\text { (MIMO) }\end{array}$ & $\begin{array}{l}\text { Later } 2008- \\
\text { early } 2009\end{array}$ & \\
\hline $4 \mathrm{G}$ & $\begin{array}{l}\text { 100Mbps- } 1 \\
\text { Gbps }\end{array}$ & $\begin{array}{l}50 \mathrm{Mbps}-500 \\
\mathrm{Mbps}\end{array}$ & $\begin{array}{l}\text { Unified IP and } \\
\text { seamless } \\
\text { combination of } \\
\text { BroadBand }\end{array}$ & WiMax, LTE & 2011 & $\begin{array}{c}1700-2600 \\
\mathrm{MHz}\end{array}$ \\
\hline
\end{tabular}




\section{a) Infrastructure of Network}

In $5 \mathrm{G}$ network both voice and IP based system would be embedded into single unit to maintain end to end quality services

\section{b) Encryption}

Encryption means changing data into unreadable format so that third party will not be able to understand. Maintaining data encryption in $5 \mathrm{G}$ will be big challenge because of new infrastructure and architecture proposed for network. Encryption may follow LTE principle because no problem has been noticed until yet regarding encryption. Question arises where to apply encryption? It may be applied for user and device authentication and identification

\section{c) Personification}

In $5 \mathrm{G}$ environment where trillions of devices are active detecting true sender of signals will be very difficult. Third party can send signal on behalf of others very easily and there may be a chance of Denial of service attack in 5G scenario

\section{d) Attack at Topmost Layer of Network Architecture}

Final purpose of any generation of network is to provide better service to consumer for that network is divided into different layers. Uppermost layer is always in touch with user, and its performance effect all other layers as well as overall network. For proper functioning of $5 \mathrm{G}$ application layer must be bug free.

\section{e) Payment Issues}

$5 \mathrm{G}$ network may consist of multiple networks and various services each one has its own charges, maintaining and billing all the details would be a tedious task in the network.

\subsection{REQUIREMENT OF 5 G}

\section{a) Data Rate}

Data rate is the amount of data transfer per second per unit area. Considering 5G's scenario it would be 1000 times more than current $4 \mathrm{G}$ network.

\section{b) Latency}

$4 \mathrm{G}$ has latency up to $15 \mathrm{~ms}$, due to future demand of services like online gaming and virtual reality, latency in $5 \mathrm{G}$ network should not exceed $1 \mathrm{~ms}$.

\section{c) Energy and Cost}

It is stated by researcher in 5G network cost and energy consumption will reduce. Energy and cost is measured in network with Joules/bit and cost/bit will fall by 100 folds in $5 \mathrm{G}$ network.

\section{d) Battery}

Conserving battery life is the main concern of $5 \mathrm{G}$ network consumption of battery life will reduce by 10 times than in existing $4 \mathrm{G}$ network. 
Table 5. Shows Requirement for 5G Mobile Network

\begin{tabular}{|c|c|c|}
\hline \multicolumn{2}{|c|}{ Requirement } & value \\
\hline Data Rate & Upload & $500 \mathrm{Mbps}-5 \mathrm{Gbps}$ \\
\cline { 2 - 3 } & Download & $1-10 \mathrm{Gbps}$ \\
\hline Latency & $1 \mathrm{~ms}$ \\
\hline Energy and Cost & 100 times less than present consumption \\
\hline Battery & 10 times more than current consumption \\
\hline Reliability & $99.9 \%$ \\
\hline
\end{tabular}

\subsection{ENABLing TeChNOLOGY For 5G}

To fulfil the above mentioned requirements of $5 \mathrm{G}$, this can offer more reliable, accurate, secure and fast network to the user. A lot of modification is needed in current technologies, some of them is suggested in below [3], [5]-[9], [23]:

\section{a) Densification of Network}

Densification of network is done through deployment of large number of small cells; decreasing cell size is a big challenge for researchers. Most recent development is in Japan where cell spacing is reduce to $1 / 10$ th of square kilometre.

\section{b) Massive MIMO}

MIMO was introduced in year 2006. It considers spatial dimensions of communication, if multiple antennas are available at the Base Station. This technique harnesses the multiplexing feature to get better results. Multi user-MIMO is included into 3GPP LTE- advanced standard, still higher capacity is yet to achieve. In VLM-MIMO, number of antennas per cell is larger than number of user, resulting in many desirable features.

\section{c) Millimeter (Mm-Wave) Signals}

In search of free frequency band researchers found $30-300 \mathrm{GHz}$ are freely available bandwidths. Total available spectrum in this range is 200 times greater than current used frequency i.e. $3 \mathrm{GHz}$.

\section{d) Direct Device to Device (D2D)}

It is exchange of data between mobile devices without base station in between, it reduces load in network devices which has to handle hundreds and thousands of requests simultaneously. It has to deal with heterogeneity of network, to support heterogeneity multiple protocols has been decided.

\section{e) Full Duplex Wireless}

Full duplex enable both side to transmit data simultaneously in same frequency band, it has numerous benefit it increases physical layer capacity up to twice and also improves latency and security at physical layer.

\section{Cognitive Radio}

Cognitive Radio was defined as follows:

Cognitive Radio $=$ Software defined Radio + Knowledge Base + Decision Making 
Cognitive Radio was proposed by Joseph Mitola at a conference in year 1999, in general sense cognitive radio can be defined as it is an intelligent radio, where transceivers are reconfigurable are able to adapt itself according to new network condition [15] . In many parts of world, Cognitive Radio basically covers two main areas of working they are Full Cognitive Radio which takes care of all the network parameters change taking place, it modify those parameters wherever change is required to optimize the network and other is spectrum sensing, spectrum is underutilized because researchers has observed that it is time and location which is important factor for percent utilization of available spectrum. For detecting and allocation of vacant spectrum, Cognitive Radio would be the best choice. This concept is known as Dynamic Spectrum Access. After detection of presence of vacant band cognitive Radio will adopt policy called Spectrum Pooling Policy where free bands are immediately filled with OFDMA sub bands.

\subsection{Key Terms In The Cognitive Radio}

\section{a) Spectrum Sensing}

Cognitive Terminal switches from one available frequency to best available frequency band.

\section{b) Spectrum Sharing}

Sharing of resource occupied by licensed user especially, spectrum band without affecting neighbour licensed users.

\section{c) Sensing Based Spectrum}

In this approach cognitive methods are implemented to get whether licensed user is licensed user is using then CR user transmit its data otherwise Cognitive Radio user lower its Transmitting Power.

\subsection{Cognitive Cycle}

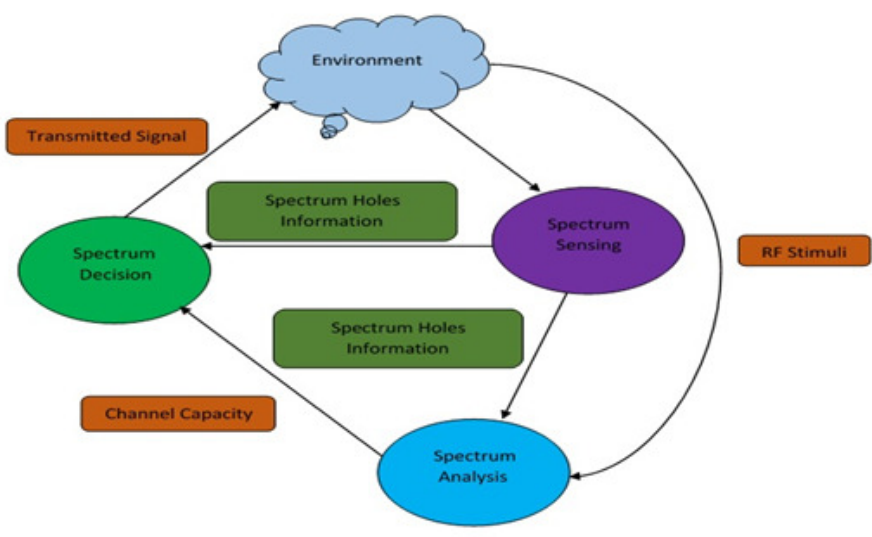

Figure 4 Showing Cognitive Cycle[24]

\subsection{Cognitive RAdio ArChitecture}

Before suggesting design of the CR researcher were handling two basic problems in it i.e. in CR devices can change its transmission mode any time which may lead to the ambiguity for the CR algorithms? And another problem faced by researcher was change in bandwidth i.e. users have mobility that they can move from one location to another location having different Bandwidth 
range in this case adjustment has to be done. Keeping above mentioned problems in scenario researcher suggested architecture of cognitive radio, it has three basic sub systems mentioned below:

- Cognitive unit for making decision which totally based on input provided.

- SDR unit whose operating software provide operating environment.

- Another component for determining signal and user characteristics.

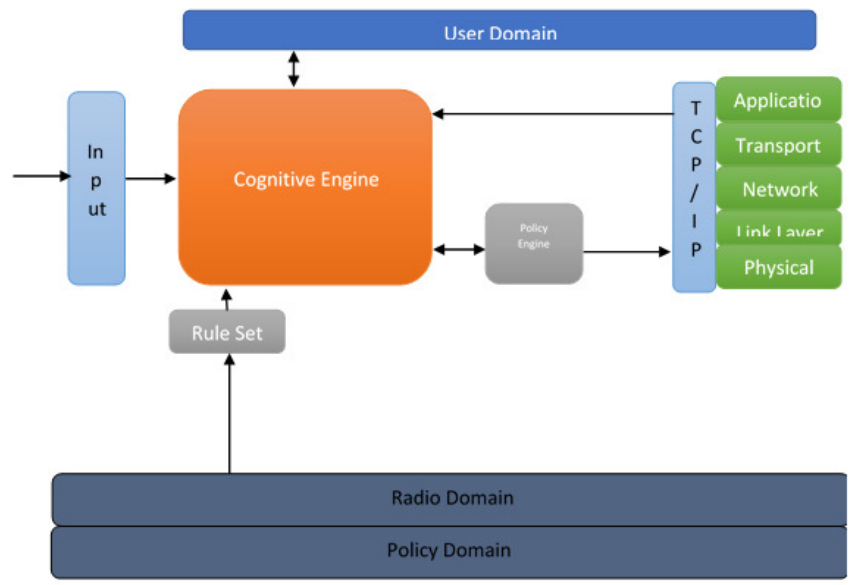

Figure 5 Shows Architecture of Cognitive Radio [25]

\subsection{TECHNIQUES For COGNITIVE ENGINE}

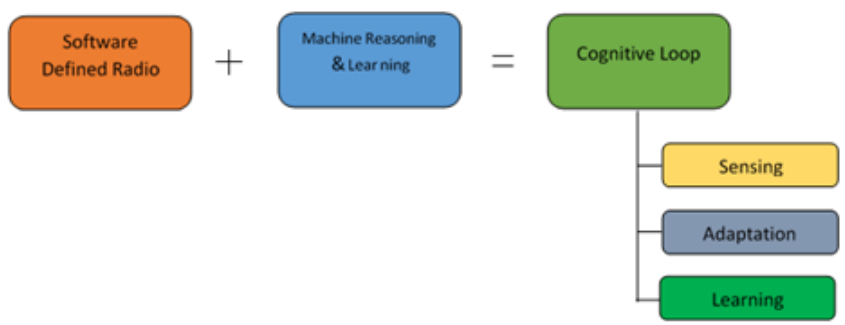

Figure 6 Showing Techniques Used to Implement Cognitive Engine

Mitola in his introductory paper of CR, suggested functional model of ideal CE that contain different phases like observe, orient, plan, decide, act and learn. Looping generally starts from observe passing response to another stage in sequence. In the below mentioned figure there is presence of two loops sequences in one loop known as sensing and adaptation loop, following is the sequence:

\section{Observe, Orient, plan, Decide and Act}

In another loop called as learning loop, sequence is process of finding (Decide), forming (Plan), using (Act) and accumulating Knowledge (Learn). 


\subsection{Functional Model Of Cognitive Engine}

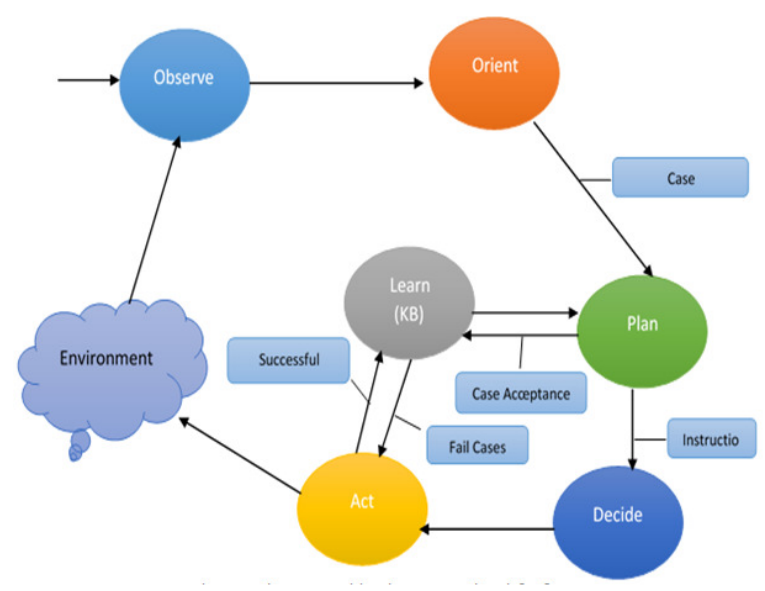

Figure 7 Shows Cognitive Loop at Two Levels[26]

There are some building blocks of CE, which can do the work in cognitive loop when together.

\section{a) Modelling System}

Modelling part take care of observe stage of cognitive loop and sensing function. System is capable of handling in form of user domain, wireless domain and policy domain, then it perform identification, integration and abstraction of input information and prior knowledge to make machine under stable model.

\section{b) Knowledge Base}

It consist of knowledge collected from prior experience and temporary network condition feed in two way manually and by gathering information from different network devices.

\section{c) Reasoning Engine}

Most important component and also known as brain of CE which help in simulation of orient, plan, decide and act belonging to adaptation loop with the help of KB.

\section{d) Learning Engine}

It is also known as futuristic brain of CE. It accumulate feedback of action taken by $\mathrm{CE}$ and stores effect of result, store it as knowledge into knowledge base.

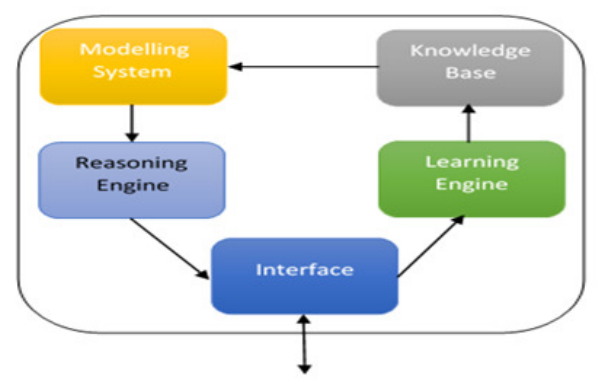

Figure 8 Showing Basic Components of Cognitive Engine 


\subsection{Key Advantages Of Cognitive Radio}

Cognitive Radio some Key benefits over other competitor methods in reference to frequency, time, space, modulation, power and other parameters

\section{a) Spectrum Efficiency}

Increasing spectrum efficiency will satisfy future demand of user which is one of the basic goal of cognitive radio.

\section{b) Higher Bandwidth}

When demand is required CR can support higher bandwidth services.

\section{c) Avoiding sudden drop of services}

When network condition is not proper instead of sudden drop of services there is grace full degradation of services.

\section{d) Better Quality of Services}

Quality of services is provided by govern by features like latency, data rate, cost and other parameters which in turn improves availability and reliability of wireless sensor network.

\section{e) Hardware platform independence}

CR supports hardware capable of handling support soft wares of various type.

\section{Spectrum Sensing Techniques Using Cognitive Radio}

Spectrum is valuable resource in network, so proper and effective utilization is recommended. In network, users are generally of two type licensed and unlicensed. Licensed user own rights over spectrum but it was found in survey that approximately $85 \%$ of spectrum is used even in the peak period of use and it may reduce to less than $15 \%$ in free periods [27] hindering basic goal of the network i.e. proper utilization of all the available resources due to this reason spectrum sharing between licensed and unlicensed user without interference in services of licensed user was proposed by researchers. Spectrum sharing is a complex problem which involve various sub process, one of the major sub process is spectrum sensing where unlicensed user has to sense for free bandwidth of licensed user. These free bandwidth slot is called as spectrum holes and unlicensed user has to transmit its signal in this very duration, there are two major type of spectrum holes temporal and spatial. Temporal spectrum hole is time dependent and spatial is geographical area dependent which requires complex signal processing. Presence and absence of spectrum holes is shown in the figure. Spectrum holes is also categorize in to three categories based on interference produced by signals these are black space, grey space and white space. Black space is totally dominated by low power interference, grey is partially dominated by interference and white is completely free from any kind of RF interference except white Gaussian noise. CR helps with its in build feature of intelligence to find out vacant band intelligently for that various algorithm were proposed some of the major algorithms are explained below 


\subsection{ENERGY DETECTION BASED}

Energy detection based approach is simple it works on detection of energy in the channel if it is below threshold then there is absence of primary User and above it means Primary User is active. Time and frequency domains are analyzed with the help of Fast Fourier Transform to find out exact calculation of vacant Bandwidth [17].

\subsubsection{TIME DOMAIN ENERGY DETECTION}

Based on Research work proposed by Urleowitch detection of priory measured signal and noise variance can be measured in AWGN [17]

\section{A.BPF}

Input signal $y(t)$ is passed through BPF with central frequency $\mathrm{f}_{0}$ and Bandwidth $\mathrm{w}$ with the transfer function.

$$
\mathbf{H}(\mathbf{f})=\left\{\begin{array}{l}
\frac{2}{\sqrt{\mathbf{N}_{0}}}\left|\mathbf{f}-\mathbf{f}_{\mathbf{0}}\right| \leq \mathbf{w} \\
0, \quad\left|\mathbf{f}-\mathbf{f}_{0}\right|>w
\end{array}\right.
$$

Where $\mathrm{N}_{0}$ is one sided noise power spectral density. It helps in normalizing false alarm and detection problem in above mentioned formula.

Squaring Device

After BPF signals get squared

Integration

Then signals are integrated in period of slot ' $T$ ', in comparison with received signal $\lambda$

$$
\left\{\begin{array}{c}
H_{0}: y(t)=w(t) \\
H_{1}: y(t)=x(t)+w(t)
\end{array}\right.
$$

$\mathrm{H}_{0}$ is no signal transmitted and $\mathrm{H}_{1}$ is signal transmitted. $\mathrm{X}(\mathrm{t})$ is unknown deterministic transmitted signal and $\mathrm{w}(\mathrm{t})$ is AWGN with zero mean and variance is equal to $\sigma^{2}=w N_{0}$ and $\mathrm{SNR}$ is expressed as $\gamma=\frac{\sigma_{s}^{2}}{\sigma_{n}{ }^{2}}$ where $\sigma_{\mathrm{s}}^{2}$ variance of signal and $\sigma_{\mathrm{n}}^{2}$ is noise variance. Construction of noise signal is done with the help of Shannon's sampling formula

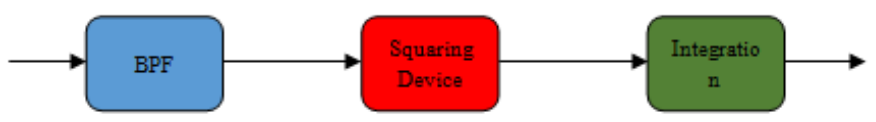

Figure 9 Showing Components of Time Domain Energy Detector [26][17]

$$
n(t)=\sum_{i=-\infty}^{+\infty} n_{i} \sin (2 w t-i)
$$


Wheresin $(x)=\frac{\sin \pi x}{\pi x}$ is normalized $\sin$ function an $\mathrm{d} n_{i}=n\left(\frac{i}{2 w}\right)$ is $i^{\text {th }}$ noise sample and test sample is calculated as

$$
V=\int_{0}^{\tau}(n(t))^{2} d t \approx \frac{1}{2 w} \sum_{i=1}^{2 \tau w} n_{i}{ }^{2}
$$

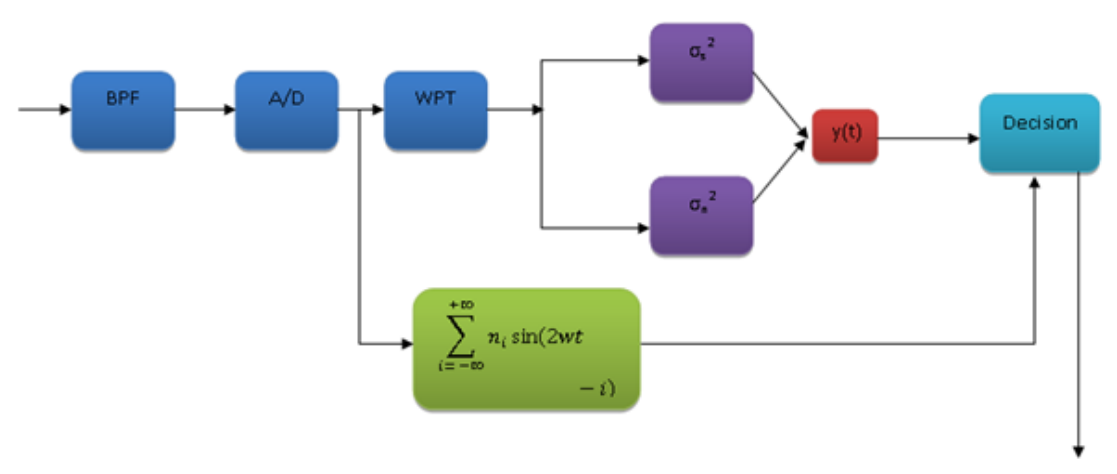

Figure 10 Shows Flow of Working In Energy Detection Based Sensing [24]

\subsection{WAVEFORM BASED SENSING}

Basis of working in this method is to know patterns. There exist various type of patterns like preambles, midambles, regularly transmitted pilot pattern, spreading sequence and other are used to sense whether received signal is copy of itself [17]. Using some derivation explained below we can find out Primary User:

$$
\mathbf{y}(\mathbf{n})=\mathbf{w}(\mathbf{n})+\mathbf{s}(\mathbf{n})
$$

Where $\mathrm{s}(\mathrm{n})$ is the signal to be detected, $\mathrm{w}(\mathrm{n})$ is additive white Gaussian Noise sample and $\mathrm{n}$ is sample index. Decision metric for the energy detector is written as:

$$
\mathbf{M}=\sum_{\mathbf{n}=\mathbf{0}}^{\mathbf{N}}|\mathbf{y}(\mathbf{n})|^{2}
$$

Where $\mathrm{N}$ is size of observation vector

$$
\mathbf{M}=\mathbf{R e}[\mathbf{y}(\mathbf{n}) \mathbf{s} *(\mathbf{n})]
$$

Where $*$ is a conjugation operation.

In the absence of primary user metric value is

$$
\mathbf{M}=\operatorname{Re}\left[\sum_{n=1}^{\mathbf{n}} \mathbf{w}(\mathbf{n}) \mathbf{s} *(\mathbf{n})\right]
$$

In the presence of Primary User 


$$
M=\sum_{n=1}^{N}|s(n)|^{2}+\operatorname{Re}\left[\sum_{n=1}^{n} w(n) s *(n)\right]
$$

Comparing values of $\mathrm{M}$ with the threshold value called $\lambda_{\mathrm{E}}$ then detect the presence and absence of Primary user. From experiment result stated in [17] waveform based sensing can outperform energy based sensing in reliability, convergence time and performance will keep on increasing as known signal pattern increases

\subsection{CyClostationary BASEd SENSING}

Cyclostationary is a feature possessed by signal due to statistical value like mean and autocorrelation or periodicity so they are used for vacant band detection of primary user and differentiate between noise and Primary user signal because there exist difference in the property of noise and primary user signal i.e. noise has no co-relation between there signals whereas in primary user signals are possessing periodicity property.

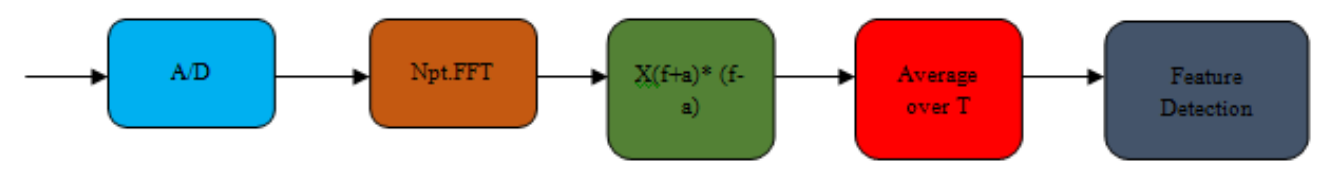

Figure 11 Shows Working Model of Cyclostationary based Sensing [24]

\subsection{RAdio IdENTIFICATION BASED SENSING}

All properties of primary user stored in advance this is done to predict presence of primary user accurately. Two major techniques were adopted for it i.e. feature extraction and classification [17]. Goal of these techniques are just to identify the transmission device and technology, so that optimal result could be achieved. For purposes of feature extraction two major method are initial mode identification (IMI) and alternative mode identification (AMI)[17]. After achieving different features about network classification algorithms are used, purposes of this is to extract proper device and technology.

\subsection{MATCHED FILTERING}

This is most optimal method of primary user when transmitted signal is known, this is because time complexity of decoding false alarm and distraction from original signal is very small but implementation time complexity is very large. There are certain constraints for implementation of this method, some parameters has to be known in advance like bandwidth, operating frequency, modulation type, pulse shaping and frame format [17][24].

\subsection{Hybrid TeChNiQue: COHERENT / EnERgy DETECTION BASEd SENSING}

As the name suggest hybrid approach mixes best features of coherent and energy detection method with the goal to remove all the loop holes in the given method. Energy detection based sensing does not requires any prior knowledge of primary users' transmitted signal, but performance degrades for low SNR value. Coherent sensing require the primary user to transmit known bit stream but offers more reliable performance at low SNR value.

Paper proposed by Moghini et al. [24] hybrid approach was discussed in which signal has pilot symbols for synchronization purposes and at the receivers end pilot position was known in prior. In this experiment authors has found that all the previous loop holes of both the methods were removed but with dear cost of time complexity. 
Table 6 Shows Comparison between Different Spectrum Sensing Algorithms [28]

\begin{tabular}{|c|c|c|c|c|c|c|}
\hline $\begin{array}{l}\text { Sensing } \\
\text { Methods/ } \\
\text { properties }\end{array}$ & $\begin{array}{c}\text { Energy } \\
\text { Detection }\end{array}$ & Coherent & $\begin{array}{l}\text { Match } \\
\text { filter }\end{array}$ & $\begin{array}{c}\text { Radio } \\
\text { Identification }\end{array}$ & Cyclostationary & Hybrid \\
\hline $\begin{array}{l}\text { Detection } \\
\text { Accuracy }\end{array}$ & $\begin{array}{l}\text { High with } \\
\text { high SNR } \\
\text { value }\end{array}$ & $\begin{array}{l}\text { Better } \\
\text { performance } \\
\text { irrespective of } \\
\text { SNR }\end{array}$ & $\begin{array}{l}\text { Best } \\
\text { performance at } \\
\text { every SNR }\end{array}$ & $\begin{array}{l}\text { Higher } \\
\text { dimensional } \\
\text { knowledge lead } \\
\text { to higher } \\
\text { accuracy }\end{array}$ & $\begin{array}{l}\text { Performance is good } \\
\text { at each SNR }\end{array}$ & $\begin{array}{l}\text { Pilot symbols } \\
\text { effect } \\
\text { performance } \\
\text { here if it } \\
\text { known } \\
\text { accuracy is } \\
\text { high }\end{array}$ \\
\hline Complexity & $\begin{array}{l}\text { It requireless } \\
\text { time } \\
\text { complexity } \\
\text { but number of } \\
\text { sample for } \\
\text { convergence } \\
\text { is always } \\
\text { high. }\end{array}$ & $\begin{array}{l}\text { It has average } \\
\text { time } \\
\text { complexity as } \\
\text { well as it } \\
\text { require less } \\
\text { number of } \\
\text { samples for } \\
\text { convergence }\end{array}$ & $\begin{array}{l}\text { Worst time } \\
\text { complexity but } \\
\text { it converges } \\
\text { with very few } \\
\text { samples }\end{array}$ & $\begin{array}{l}\text { Time complexity } \\
\text { is high }\end{array}$ & $\begin{array}{l}\text { It has average time } \\
\text { complexity and } \\
\text { require less number } \\
\text { of samples for } \\
\text { convergence }\end{array}$ & $\begin{array}{l}\text { It has average } \\
\text { time } \\
\text { complexity, } \\
\text { with single } \\
\text { conditionall } \\
\text { pilot symbols } \\
\text { locations hes to } \\
\text { be known in } \\
\text { advance. }\end{array}$ \\
\hline Robustness & $\begin{array}{l}\text { Does not } \\
\text { require any } \\
\text { prior } \\
\text { information } \\
\text { about primary } \\
\text { user signal }\end{array}$ & $\begin{array}{l}\text { Pattern must } \\
\text { present in the } \\
\text { primary user } \\
\text { signal, it is } \\
\text { difficult to } \\
\text { locate exact } \\
\text { position of } \\
\text { pattern }\end{array}$ & $\begin{array}{l}\text { Some } \\
\text { parameter has } \\
\text { to be known in } \\
\text { advance }\end{array}$ & $\begin{array}{l}\text { Highly robust if } \\
\text { clas sification of } \\
\text { network feature } \\
\text { is done in proper } \\
\text { manner }\end{array}$ & $\begin{array}{l}\text { Receiving end must } \\
\text { have awareness } \\
\text { about periodic } \\
\text { features of primary } \\
\text { user }\end{array}$ & $\begin{array}{l}\text { Primary user } \\
\text { signal must } \\
\text { contain pilot } \\
\text { signal. }\end{array}$ \\
\hline $\begin{array}{l}\text { Design } \\
\text { choices }\end{array}$ & $\begin{array}{l}\text { Threshold } \\
\text { frequency } \\
\text { decision is } \\
\text { difficult }\end{array}$ & $\begin{array}{l}\text { Receiver } \\
\text { pattern can be } \\
\text { increased to } \\
\text { improve } \\
\text { accuracy }\end{array}$ & $\begin{array}{l}\text { Better choice } \\
\text { of feature lead } \\
\text { to better } \\
\text { accuracy }\end{array}$ & $\begin{array}{l}\text { Determination of } \\
\text { exact feature is } \\
\text { difficult may lead } \\
\text { to error in } \\
\text { estimation of } \\
\text { technology }\end{array}$ & $\begin{array}{l}\text { Cyclostationary } \\
\text { features were } \\
\text { included to improve } \\
\text { accuracy }\end{array}$ & $\begin{array}{l}\text { Increase pilot } \\
\text { symbols to } \\
\text { improve } \\
\text { accuracy. }\end{array}$ \\
\hline
\end{tabular}

In early stage of mobile generation Network architecture is centralize and with the new generation of mobile technology it started shifting towards cluster approach of mobile network and hence need to work in both cluster and integrated form. When discussion on 5G mobile technology based on Cognitive Radio that means it support both integrated and cluster architecture as well, this similarities between 5g and CR [19] which inspire researchers to use both of them together. Transmitting and receiving node in the mobile technology is known as terminal. 5G is combination of many heterogeneous mobile network, hence it has to support all technology at its various technology without affecting quality of service. Cognitive Radio provides flexibility in configuration of radio which switches between many mobile technologies. According to literature Cognitive Radio technology in 5G is generally based on Cognitive Engine design which is using different techniques like Genetic Algorithm, statistical model and nature inspired algorithms. Cognitive Radio is implemented in 5G for managing resources and adaptation.

Resource management is a major challenge because achieving better resource management is one of the goal of $5 \mathrm{G}$ system which cannot be achieved without help of cognitive radio, it induces intelligent system capability for taking real time decision in the network resulting in better allocation of resources in the network. Researcher has divided cognitive radio resources into in to three major categories radio resources, computing resources and application resources [19]. Another major application of cognitive radio is adaptation which means selecting proper value of cognitive radio parameter 


\section{Conclusion}

In this paper we have seen detailed survey on both $5 \mathrm{G}$ and $\mathrm{CR}$ technologies, as stated in the introduction part CR act as backbone of 5G network technology in the later part of paper we were trying to prove it. Since we know that $5 \mathrm{G}$ suffer from some implementations complexities we have also seen each problem in its detail and how to rectify those ones. We have also gone through many CR algorithms purpose of it is to know about scope of each spectrum sensing algorithm. Finally in literature survey along with contribution of researchers, a quick look on smart antenna is done. In future we would overcome the existing problem for $5 \mathrm{G}$ using cognitive radio like detection of primary user using less amount of energy, removing interference so that primary user and noise can be differentiated easily and better allocation of bandwidth.

\section{REFERENCES}

[1] F. Boccardi, T. L. Marzetta, and B. Labs, "Five Disruptive Technology Directions for 5G," no. February, pp. 74-80, 2014.

[2] T. Next, G. Mobile, N. Alliance, T. Next, G. Mobile, N. Alliance, A. S. Engineering, T. Federal, C. Commission, T. Federal, and C. Commission, "For other uses, see 5G (disambiguation)."

[3] J. G. Andrews, S. Buzzi, W. Choi, S. V. S. V. Hanly, A. Lozano, A. C. K. A. C. K. Soong, and J. C. J. C. Zhang, "What will 5G be?," IEEE J. Sel. Areas Commun., vol. 32, no. 6, pp. 1065-1082, 2014.

[4] P. Banelli, S. Buzzi, G. Colavolpe, A. Modenini, F. Rusek, and A. Ugolini, "5G Networks : Who Will," no. October, pp. 80-93, 2014.

[5] S. Chen and J. Zhao, "The Requirements , Challenges, and Technologies for 5G of Terrestrial Mobile Telecommunication," no. May, pp. 36-43, 2014.

[6] C. S. Engineering, "5G Technology of Mobile Communication,” pp. 1265-1275, 1956.

[7] A. Gohil, H. Modi, and S. K. Patel, "5G Technology of Mobile Communication : A Survey," pp. 288292, 2013.

[8] C. Paper, "5G technology of mobile communication: A survey 5G Technology of Mobile Communication : A Survey," no. October, 2015.

[9] R. S. Yarrabothu, "A Survey Paper On 5G Cellular Technologies - Technical \& Social Challenges," vol. 11, no. June, pp. 98-100, 2015.

[10] C. X. Mavromoustakis and C. D. Dimitriou, "Joint Energy and Delay-aware Scheme for 5G Mobile Cognitive Radio Networks," pp. 2624-2630, 2014.

[11] N. For, "Enhanced Multi-Parameter Cognitive Architecture for Future Wireless Communications," no. July, pp. 86-92, 2015.

[12] X. Zhang, W. Cheng, and H. Zhang, "Heterogeneous Statistical QoS Provisioning Over 5G Mobile Wireless Networks," no. December, pp. 46-53, 2014.

[13] M. Bellanger, D. Mattera, M. Tanda, and D. Ingegneria, "Lapped-OFDM as an alternative to CPOFDM for 5G asynchronous access and cognitive radio," no. 2, pp. 5-9, 2015.

[14] C. Technology, R. Gandhi, P. Vishwavidyalaya, and P. De, "Resource Allocation in 5G using Modified Random Forest Algorithm,” 2016.

[15] "Cognitive Radio : Making Software Radios More Personal."

[16] F. Ge, Q. Chen, Y. Wang, C. W. Bostian, T. W. Rondeau, and B. Le, "Cognitive Radio: From Spectrum Sharing to Adaptive Learning and Reconfiguration," 2008.

[17] I. C. Surveys, “A Survey of Spectrum Sensing Algorithms for Cognitive Radio Applications," vol. 11, no. 1, pp. 116-130, 2009.

[18] K. M. Thilina, N. Saquib, and E. Hossain, "Machine Learning Techniques for Cooperative Spectrum Sensing in Cognitive Radio Networks,” IEEE J. Sel. Areas Commun., vol. 31, no. 11, pp. 2209-2221, 2013.

[19] C.-I. Badoi, N. Prasad, V. Croitoru, and R. Prasad, "5G Based on Cognitive Radio," Wirel. Pers. Commun., vol. 57, no. 3, pp. 441-464, 2011.

[20] X. Hong and J. Wang, "Cognitive Radio in 5G : A Perspective on Energy-Spectral Efficiency Tradeoff," no. July, pp. 46-53, 2014.

[21] S. Antennaspropagation, "8 MEMs Mic Array Matrix Creator is the first mic array."

[22] S. Antenna, "4G Communication Smart Antenna Advantages of Smart Antenna: Disadvantages of Smart Antenna :" 
[23] "Functional Architecture for 5G Mobile Networks," no. October, 2015.

[24] C. Engineering, "Spectrum Sensing Methods In Cognitive Radio," 2011.

[25] D. Xu, L. I. Ying, and W. E. I. Shengqun, "Design and implementation of a cognitive engine functional," vol. 57, no. 28, pp. 3698-3704, 2012.

[26] M. A. Abdulsattar and Z. A. Hussein, "Energy Detection Technique For Spectrum Sensing In Cognitive Radio : A Survey,” vol. 4, no. 5, pp. 223-242, 2012.

[27] A. D. Katre and K. R. Desai, "Cooperative Spectrum Sensing with Weighted Clustered Architecture," vol. 1, no. 2, pp. 40-44, 2013.

[28] S. Parsons, "Literature Review of Cognitive Radio Spectrum Sensing EE 359 Project," 2014.

\section{AuThors}

Parnika De obtained the B.Tech. Degree in Electronics and Communication Engineering from Lovely Professional University, India, in 2012 and the M.Tech. Degree from the National Institute of Technical Teachers' Training and Research, Bhopal, India in 2016. Currently, she has presented her Research Proposals in some of the pioneer institutes for admission in Ph.D. degree in the field of "Intelligent Techniques for Resource Allocation in 5G". Miss. De has attended numerous seminars on wireless communication, 5G, Cognitive Radio and Machine Learning and she also had experience of working in Software development industry. Her areas of research include Next Generation Cellular Networks and Cognitive Radio Networks.

Shailendra Singh received his bachelor degree in Computer Science and Engineering from AMIE, India in 1994 and master's degree and Ph.D. deSree from Rajiv Gandhi ProudyogkiVishwavidlaya, Bhopal, India in 2004 and 2010 respectively. He is currently working as professor in Department of Computer Engineering and Application, National Institute of Technical Teachers' Training and Research, Bhopal, India. His research interests include development of classification algorithms for cyber-attack detection system

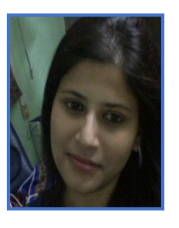
using machine learning technique like support vector machine. He received best paper award for "Improved Support Vector Machine for Cyber-Attack Detection", proceeding in world congress on Engineering and Computer Science (WCECS) 2011, October 19-21, 2011, San Francisco, USA. He is member s of various technical societies like IEEE, IACSIT (Singapore), ISTE (New Delhi), Microsoft Corporation (USA), and Institute of Engineers (India). He also chaired technical session of many conferences both national and international. He has published more than 30 research papers in the international journals and conferences. His research interest also include finger print matching. hailendra Singh received his bachelor degree in Computer Science and Engineering from AMIE, India in 1994 and master's degree and Ph.D. degree from Rajiv Gandhi ProudyogkiVishwavidlaya, Bhopal, India in 2004 and 2010 respectively. He is currently working as professor in Department of Computer Engineering and Application, National Institute of Technical Teachers' Training and Research, Bhopal, India. His research interests include development of classification algorithms for cyber-attack detection system using machine learning technique like support vector machine. He received best paper award for "Improved Support Vector Machine for Cyber-Attack Detection", proceeding in world congress on Engineering and Computer Science (WCECS) 2011, October 19-21, 2011, San Francisco, USA. He is member s of various technical societies like IEEE, IACSIT (Singapore), ISTE (New Delhi), Microsoft Corporation (USA), and Institute of Engineers (India). He also chaired technical session of many conferences both national and international. He has published more than 30 research papers in the international journals and conferences. His research interest also include finger print matching. 